\title{
STUDY OF RELATIONSHIP OF PSYCHOSOCIAL FACTORS WITH SMOKING IN NORTHERN POPULATION
}

DOI: 10.36740/WLek202103125

\author{
Natalia V. Borisova, Sardana V. Markova, Irina Sh. Malogulova \\ INSTITUTE OF MEDICINE, NORTH-EASTERN FEDERAL UNIVERSITY, YAKUTSK, RUSSIA
}

\begin{abstract}
The aim: Of our study was to identify the relationship between the main risk factors for heart disease and social factors among northern population.

Materials and methods: We polled 3092 native and non-native habitants of the Sakha Republic (Yakutia). The poll consists of several sections. It includes questions related to social, demographic and life record data, heredity, physical activity and unhealthy habits.

Results: Among the people diagnosed with hypertension (HT), there are more smokers than among the people without this medical condition. On the contrary, in the group of people diagnosed with HT at the examination for taking blood pressure, there were fewer smokers than in the group, in which HT was not registered. Patients with CHD, Myocardial infarction (MI) in past medical history, cerebrovascular accident (CVA) and type 2 diabetes (T2D), are smokers to the same degree as the other group. This indicates that this category of the examined are exposed to the risk of cardiovascular aggravations. We determined a high spread of psychosocial risk factors for the examined respondents - the relationship between smoking, overweight, obesity, abdominal obesity and HT, and the level of education, marital status and labor specificity. The increase in the level of education is associated with fewer amounts of smokers among both non-native and native habitants. Overweight is more frequently observed for the people who are not single, have low level of education and are engaged in manual labor. In particular, it is applicable to native habitants.

Conclusions: Abdominal obesity did not have any relationship with psychosocial factors for native habitants. However, in relation to non-native habitants, overweight, obesity, abdominal obesity and HT are associated with marital status (married) and with manual labor.
\end{abstract}

KEY WORDS: smoking, risk factors, psychosocial risk

Wiad Lek. 2021;74(3 p.l):517-522

\section{INTRODUCTION}

Smoking is commonly recognized as a reason for development of various diseases. It is a cause of deaths for $50 \%$ of smokers (half of whom die from cardiovascular diseases), which could have been avoided. Such aspects of lifestyle as smoking and psychosocial factors lead to cardiovascular diseases [1]. Many countries consider that this problem results in premature mortality and increased costs of healthcare system, which damages social and economic spheres.

Regardless of decrease observed in smoking tendency in Europe, it is still a common phenomenon among people with low level of education. Level of education determines the difference in the amount of people who give up smoking in many European countries [2].

Smoking-related risk primarily depends on the number of cigarettes smoked per day, taking into consideration an obvious dose-addiction effect. At the same time, there is no lower limit with the absence of negative effect [3].

The accumulated data indicates the increase of coronary heart disease (CHD) risk for passive smokers to a greater extent than it was expected $[4,5]$. Cardio vascular disease (CVD) risk increases by about $30 \%$ for a non-smoker person living with a smoker partner [6,7], or for an employee who inhales cigarette smoke at the workplace $[8,9]$.

\section{THE AIM}

The aim of our study was to identify the relationship between the main risk factors for heart disease and social factors among northern population.

\section{MATERIALS AND METHODS}

We polled 3092 native and non-native habitants of the Sakha Republic (Yakutia). The poll consists of several sections. It includes questions related to social, demographic and life record data, heredity, physical activity and unhealthy habits. A regular smoker shall be considered a person who has been smoking at least one cigarette per day for the last 12 months.

Social status was estimated using standard questionnaire. We estimated such parameters as education level and marital status.

In accordance with level of education we divided the examined into four groups:

Group 1: people with primary (or lower) level of education. Group 2: people with vocational education.

Group 3: people with secondary education.

Group 4: people with a degree.

In accordance with marital status we divided the examined into 4 groups: 
Natalia V. Borisova et al.

Table I. Smoking rate for native population of the Sakha Republic (Yakutia).

\begin{tabular}{ccccc}
\hline Age groups & All & Men & Women & P \\
\hline All & 37.4 & 52.6 & 31.9 & $<0.001$ \\
\hline Age 18-59 (1) & 42.3 & 57.8 & 36.6 & $<0.001$ \\
\hline Age 60+ (2) & 20.9 & 35.4 & 16.2 & $<0.001$ \\
\hline $\mathrm{P}_{1-2}$ & $<0.001$ & $<0.001$ & $<0.001$ & \\
\hline
\end{tabular}

Table II. Smoking rate among native population of the Sakha Republic (Yakutia) districts.

\begin{tabular}{|c|c|c|c|c|}
\hline Age groups & All & Men & Women & $\mathbf{P}$ \\
\hline \multicolumn{5}{|c|}{ Tattinsky District } \\
\hline All & 37.7 & 55.6 & 31.3 & $<0.001$ \\
\hline Age 18-59 (1) & 43.9 & 64.0 & 36.7 & $<0.001$ \\
\hline Age $60+(2)$ & 23.8 & 36.4 & 19.4 & 0.108 \\
\hline$P_{1-2}$ & $<0.01$ & $<0.05$ & $<0.01$ & \\
\hline \multicolumn{5}{|c|}{ Verkhnevilyuisky District } \\
\hline All & 31.4 & 41.1 & 29.0 & $<0.05$ \\
\hline Age $18-59(1)$ & 36.5 & 44.1 & 34.8 & 0.150 \\
\hline Age $60+(2)$ & 16.5 & 33.3 & 12.0 & $<0.01$ \\
\hline$P_{1-2}$ & $<0.001$ & 0.335 & $<0.001$ & \\
\hline \multicolumn{5}{|c|}{ Verkhoyansky District } \\
\hline All & 39.7 & 54.1 & 34.0 & $<0.001$ \\
\hline Age 18-59(1) & 44.3 & 60.9 & 37.5 & $<0.001$ \\
\hline Age $60+(2)$ & 20.9 & 24.0 & 19.4 & 0.654 \\
\hline$P_{1-2}$ & $<0.001$ & $<0.001$ & $<0.01$ & \\
\hline \multicolumn{5}{|c|}{ Eveno-Bytantaysky District } \\
\hline All & 43.5 & 58.7 & 35.1 & $<0.001$ \\
\hline Age 18-59(1) & 46.9 & 61.3 & 38.8 & $<0.01$ \\
\hline Age $60+(2)$ & 27.7 & 47.1 & 17.2 & $<0.05$ \\
\hline$P_{1-2}$ & $<0.05$ & 0.280 & $<0.05$ & \\
\hline
\end{tabular}

Table III. Smoking rate among native population of Yakutia having different chronic NCDs.

\begin{tabular}{cccc}
\hline & Pathology & No pathology & P \\
\hline HT (according to BP) & 29.4 & 39.1 & $<0.001$ \\
\hline HT (diagnosed by a specialist) & 38.3 & 29.1 & $<0.01$ \\
\hline Type 2 diabetes & 33.3 & 37.3 & 0.460 \\
\hline Stroke in past medical history & 46.4 & 36.9 & 0.149 \\
\hline CHD & 33.1 & 38.2 & 0.136 \\
\hline Ml in past medical history & 35.8 & 37.4 & 0.823 \\
\hline
\end{tabular}

Group 1: married or having common-law relationship.

Group 2: single.

Group 3: widow (widower).

Group 4: divorced or living apart.

Statistical data was processed by SPSS v19.0 software package. Statistic estimation includes descriptive analysis of indicators numerical characteristics (averaged values, standard deviations) and their division. We used such methods as selections comparison (Mann-Whitney U test, Student's t-test) and contingency table analysis (Fisher's exact test, Pearson's chi-squared test). Normality of distri- bution was confirmed by the Kolmogorov-Smirnov test. The results were considered significant if $\mathrm{p}<0.05$.

\section{RESULTS}

According to our data, the occurrence of smoking among adult population of the Sakha Republic (Yakutia) amounts to $37.4 \%$. There are more male smokers $(52.6 \%)$ than female $(31.9 \%)$. We noticed that there are two times less smokers among older people. This tendency is traced in both gender groups (Table I). 
Table IV. Smoking rate among non-native population of the Sakha Republic (Yakutia).

\begin{tabular}{cccccc}
\hline Age groups & All & Men & Women & P & $<0.001$ \\
\hline All & 41.8 & 62.8 & 31.4 & 33.5 & $<0.001$ \\
\hline Age 18-59 (1) & 43.5 & 63.3 & 11.3 & $<0.001$ \\
\hline Age 60+ (2) & 22.5 & 55.6 & 0.001 & \\
\hline$P_{1-2}$ & 0.001 & 0.513 & & \\
\hline
\end{tabular}

Table V. Smoking rate related to psychosocial factors.

\begin{tabular}{|c|c|c|c|c|}
\hline Factors & All & men & women & $\mathbf{P}$ \\
\hline \multicolumn{5}{|c|}{ Education level } \\
\hline $\begin{array}{l}\text { Secondary level; secondary vocational level; lower } \\
\text { than secondary level (1) }\end{array}$ & 41.3 & 54.0 & 35.9 & $<0.001$ \\
\hline Higher (2) & 25.8 & 43.5 & 21.8 & $<0.001$ \\
\hline$P_{1-2}$ & $<0.001$ & 0.111 & $<0.001$ & \\
\hline \multicolumn{5}{|c|}{ Marital status } \\
\hline Married & 37.6 & 52.0 & 31.1 & $<0.001$ \\
\hline Single & 37.0 & 54.4 & 33.2 & $<0.001$ \\
\hline$P_{1-2}$ & 0.831 & 0.684 & 0.474 & \\
\hline \multicolumn{5}{|c|}{ Labor specificity } \\
\hline Sedentary work & 27.3 & 43.8 & 23.9 & $<0.001$ \\
\hline Standing work & 35.0 & 63 & 29.4 & $<0.001$ \\
\hline Manual work & 47.8 & 58.3 & 40.6 & $<0.001$ \\
\hline Nervous work & 39.5 & 50.0 & 35.8 & 0.098 \\
\hline Domestic work & 32.6 & 40.4 & 30.4 & 0.175 \\
\hline $\mathrm{P}$ & $<0.001$ & 0.083 & $<0.001$ & \\
\hline \multicolumn{5}{|c|}{ Depression } \\
\hline Presence of depression (1) & 37.1 & 46.7 & 34.0 & 0.378 \\
\hline Absence of depression (2) & 37.0 & 51.4 & 31.7 & $<0.001$ \\
\hline$P_{1-2}$ & 0.987 & 0.718 & 0.735 & \\
\hline
\end{tabular}

Analysis of the smoking rate for native habitants from different districts of the republic has proven that the spread of smoking does not vary to a large extent; it is almost the same for all the districts and does not exceed 40\%, except for Evenko-Bytantaysky District, where the smoking rate is a bit higher (43.5\%). The higher smoking rate among men is consistent in all the districts. However, we can observe more explicit age-related gradation of the women's smoking rate (Table II).

We can observe age-related decrease in the men's smoking rate in Tattinsky and Verkhoyansky Districts. In Verkhnevilyuisky and Eveno-Bytantaysky Districts the number of young and mature men smokers is approximately equal. It is important to note that almost $60 \%$ of working-age men from the examined districts are smokers, except for men from Verkhnevilyuisky District (44.1\%). This negative situation can be observed for women as well. More than $30 \%$ of women aged 18-59 smoke (Table II).

In our study, we analyzed the smoking rate among patients with CVD and T2D (Table III). Among the people diagnosed with hypertension (HT), there are more smokers than among the people without this medical condition. On the contrary, in the group of people diagnosed with $\mathrm{HT}$ at the examination for taking blood pressure, there were fewer smokers than in the group, in which HT was not registered. Patients with CHD, Myocardial infarction (MI) in past medical history, cerebrovascular accident (CVA) and type 2 diabetes (T2D), are smokers to the same degree as the other group. This indicates that this category of the examined are exposed to the risk of cardiovascular aggravations.

The analysis of smoking rate among non-native population has shown that this risk factor is frequent for general group of the examined non-native habitants. We observed age-related decrease of this parameter (Table IV). At the same time, we noticed that the smoking rate is 2 times higher among non-native men compared to non-native women: $62.8 \%$ and $31.4 \%$ respectively. The smoking rate is high for men regardless of the age. As for non-native women, the smoking rate is 3 times higher for working-age representatives of this group, compared to the senior ones.

We did not find any differences in the smoking rate for native and non-native habitants. However, we discovered that the smoking rate for non-native men is higher than for native men. Such difference is more explicit for senior men. 
Table VI. Smoking rate related to psychosocial factors in Tattinsky District.

\begin{tabular}{|c|c|c|c|c|}
\hline Age groups & All & men & women & $\mathbf{P}$ \\
\hline $\begin{array}{l}\text { Secondary level; secondary } \\
\text { vocational level; lower than } \\
\text { secondary level (1) }\end{array}$ & 42.0 & 58.6 & 34.1 & $<0.001$ \\
\hline Higher (2) & 30.3 & 50.0 & 25.9 & 0.101 \\
\hline$P_{1-2}$ & 0.095 & 0.583 & 0.279 & \\
\hline \multicolumn{5}{|c|}{ Marital status } \\
\hline Married & 36.1 & 56.9 & 27.9 & $<0.001$ \\
\hline Single & 45.7 & 57.9 & 41.2 & 0.212 \\
\hline$P_{1-2}$ & 0.162 & 0.938 & 0.085 & \\
\hline \multicolumn{5}{|c|}{ Labor specificity } \\
\hline Sedentary work & 26.5 & 44.4 & 22.5 & 0.178 \\
\hline Standing work & 36.7 & 80.0 & 28.0 & 0.028 \\
\hline Manual work & 52.4 & 69.2 & 40.5 & 0.025 \\
\hline Nervous work & 55.2 & 85.7 & 45.5 & 0.062 \\
\hline Domestic work & 23.4 & 27.3 & 22.2 & 0.729 \\
\hline $\mathrm{P}$ & $<0.001$ & $<0.05$ & 0.164 & \\
\hline \multicolumn{5}{|c|}{ Depression } \\
\hline Presence of depression (1) & 38.3 & 40.0 & 33.3 & 0.850 \\
\hline Absence of depression (2) & 37.5 & 58.0 & 31.8 & $<0.001$ \\
\hline$P_{1-2}$ & 0.963 & 0.439 & 0.955 & \\
\hline
\end{tabular}

Table VII. Smoking rate related to psychosocial factors in Verkhnevilyuisky District.

\begin{tabular}{|c|c|c|c|c|}
\hline Age groups & All & men & women & $\mathbf{P}$ \\
\hline $\begin{array}{l}\text { Secondary level; secondary vocational } \\
\text { level; lower than secondary level (1) }\end{array}$ & 33.8 & 41.1 & 31.8 & 0.037 \\
\hline Higher (2) & 23.9 & 30.8 & 22.8 & 0.532 \\
\hline$P_{1-2}$ & 0.070 & 0.483 & 0.127 & \\
\hline \multicolumn{5}{|c|}{ Marital status } \\
\hline Married & 31.3 & 40.4 & 28.4 & 0.189 \\
\hline Single & 33.3 & 33.3 & 33.3 & 0.352 \\
\hline$P_{1-2}$ & 0.678 & 0.599 & 0.357 & \\
\hline \multicolumn{5}{|c|}{ Labor specificity } \\
\hline Sedentary work & 24.4 & 25.0 & 24.3 & 0.948 \\
\hline Standing work & 22.4 & 50.0 & 17.1 & 0.041 \\
\hline Manual work & 40.0 & 40.0 & 40.0 & 1.000 \\
\hline Nervous work & 32.3 & 33.3 & 31.9 & 0.919 \\
\hline Domestic work & 28.4 & 38.5 & 25.9 & 0.368 \\
\hline$P$ & 0.068 & 0.738 & $<0.05$ & \\
\hline \multicolumn{5}{|c|}{ Depression } \\
\hline Presence of depression (1) & 37.5 & 60.0 & 42.1 & 0.475 \\
\hline Absence of depression (2) & 38.3 & 35.7 & 29.8 & 0.337 \\
\hline$P_{1-2}$ & 0.131 & 0.278 & 0.259 & \\
\hline
\end{tabular}

In this study we analyzed the relationship between psychosocial factors and smoking, which is a key risk factor for CVDs. The smoking rate is higher for people with secondary and higher level of education among the examined native habitants. However, the rate in both groups is high for men, while it is lower for women with higher education (Table V). The relationship between smoking and labor specificity is also observed for women. Smoking rate is 
Table VIII. Smoking rate related to psychosocial factors in Verkhoyansky District.

\begin{tabular}{|c|c|c|c|c|}
\hline Age groups & All & men & women & $\mathbf{P}$ \\
\hline $\begin{array}{c}\text { Secondary level; secondary } \\
\text { vocational level; lower than } \\
\text { secondary level (1) }\end{array}$ & 42.9 & 52.0 & 38.3 & $<0.05$ \\
\hline Higher (2) & 23.1 & 75.0 & 13.6 & $<0.01$ \\
\hline$P_{1-2}$ & 0.50 & 0.367 & $<0.05$ & \\
\hline \multicolumn{5}{|c|}{ Marital status } \\
\hline Married & 39.7 & 52.6 & 35.2 & 0.181 \\
\hline Single & 38.8 & 53.1 & 34.6 & 0.059 \\
\hline$P_{1-2}$ & 0.901 & 0.973 & 0.939 & \\
\hline \multicolumn{5}{|c|}{ Labor specificity } \\
\hline Sedentary work & 20.3 & 53.8 & 13.1 & $<0.001$ \\
\hline Standing work & 37.5 & 57.1 & 33.3 & 0.237 \\
\hline Manual work & 49.5 & 60.4 & 38.3 & $<0.05$ \\
\hline Nervous work & 36.0 & 33.3 & 36.8 & 0.876 \\
\hline Domestic work & 41.0 & 38.1 & 42.1 & 0.749 \\
\hline$P$ & $<0.001$ & 0.419 & $<0.01$ & \\
\hline \multicolumn{5}{|c|}{ Depression } \\
\hline Presence of depression (1) & 23.1 & 0 & 25.0 & 0.569 \\
\hline Absence of depression (2) & 39.9 & 52.5 & 33.8 & $<0.01$ \\
\hline$P_{1-2}$ & 0.223 & 0.296 & 0.529 & \\
\hline
\end{tabular}

Table IX. Smoking rate related to psychosocial factors in Eveno-Bytantaysky District.

\begin{tabular}{|c|c|c|c|c|}
\hline Age groups & All & men & women & $\mathbf{P}$ \\
\hline \multicolumn{5}{|c|}{ Eveno-Bytantaysky District } \\
\hline $\begin{array}{l}\text { Secondary level; secondary vocational } \\
\text { level; lower than secondary level (1) }\end{array}$ & 50.4 & 62.7 & 43.2 & $<0.05$ \\
\hline Higher (2) & 29.7 & 42.9 & 26.0 & 0.222 \\
\hline$P_{1-2}$ & $<0.01$ & 0.181 & $<0.05$ & \\
\hline \multicolumn{5}{|c|}{ Marital status } \\
\hline Married & 48.7 & 58.2 & 43.2 & 0.108 \\
\hline Single & 31.4 & 66.7 & 23.8 & $<0.05$ \\
\hline$P_{1-2}$ & $<0.05$ & 0.631 & $<0.05$ & \\
\hline \multicolumn{5}{|c|}{ Labor specificity } \\
\hline Sedentary work & 38.0 & 58.3 & 33.9 & 0.112 \\
\hline Standing work & 43.5 & 60.0 & 38.9 & 0.400 \\
\hline Manual work & 56.1 & 54.2 & 58.8 & 0.767 \\
\hline Nervous work & 46.9 & 75.0 & 30.0 & $<0.05$ \\
\hline Domestic work & 12.5 & 50.0 & 0 & 0.064 \\
\hline $\mathrm{P}$ & 0.147 & 0.816 & 0.102 & \\
\hline \multicolumn{5}{|c|}{ Depression } \\
\hline Presence of depression (1) & 38.5 & 50.0 & 33.3 & 0.569 \\
\hline Absence of depression (2) & 42.8 & 59.6 & 34.0 & $<0.01$ \\
\hline$P_{1-2}$ & 0.763 & 0.706 & 0.968 & \\
\hline
\end{tabular}

higher for the representatives of professions related to manual labor. Regardless of marital status and depression, we observe high smoking rate both for men and women.
Following the detailed analysis, we can observe that the relationship between psychosocial factors and CVD risk factors varies between districts. In Tattinsky District we do not trace the relation 
of the difference factors with education level, marital status and depression. However, we can see explicit relationship between labor specificity and smoking, especially among men (Table VI).

For Verkhnevilyuisky District, the same as for Tattinsky District, we observe a clear relationship between labor specificity and smoking, especially among women (Table VII). We did not discover any differences as regards to the rest of the factors.

In Verkhoyansky District, the smoking rate is higher for women with secondary or secondary vocational level of education. However, this relationship is smoothed out in the total reference set as there is a large number of smoking men with higher education. We can see explicit relationship between labor specificity and smoking, especially among women (Table VIII). We did not discover any differences as regards to the rest of the factors.

For Eveno-Bytantaysky District, we can observe a small number of married women and women with higher education. We did not discover any relationship of smoking with the rest of psychosocial factors (Table IX).

\section{DISCUSSION}

Smoking is a recognized cause of many diseases and the cause of $50 \%$ of avoidable deaths of smokers, half of them are due to cardiovascular diseases [4].

In our study, it was found that patients with coronary artery disease, myocardial infarction (MI), acute cerebrovascular accident (ACVA), and type 2 diabetes, compared with those without these pathologies, smoke equally, which indicates a high risk of cardiovascular complications in this category of patients. The results of clinical studies and laboratory experiments conducted by Capewell S. et al. also show that a decrease in mortality from coronary heart disease can occur quickly after individual or population measures to change the diet or quit smoking [3].

Higher education levels are associated with lower smoking prevalence among indigenous and newcomers. Despite a decline in smoking prevalence in Europe, it remains widespread among people with low educational attainment; differences in the frequency of smoking cessation depending on the level of education in recent years have been observed in many European countries [6]. In previous studies, the risk associated with smoking in women is significantly higher than in men [8], which is confirmed by our study. This may be due to differences in the metabolism of nicotine, and is also confirmed by the data that women are more passive smokers, which does not reduce their risk of developing diseases of the cardiovascular system [7].

Studies carried out by many scientists $[7,8]$, as well as our data have shown that low socioeconomic status, lack of social support, stress at work and in the family, depression, anxiety, hostility, in association with smoking, increase the risk of developing cardiovascular diseases, contribute to the deterioration of the clinical course and prognosis of cardiovascular diseases.

\section{CONCLUSIONS}

We determined a high spread of psychosocial risk factors for the examined respondents - the relationship between smoking, overweight, obesity, abdominal obesity and HT, and the level of education, marital status and labor specificity. Taking into consideration high CHD occurrence and wide spread of smoking, we can assume that decrease in the spread of passive smoking will significantly improve the situation.

\section{REFERENCES}

1. Wipfli H. L., Samet J. M. Second-hand smoke's worldwide disease toll. Lancet. 2011; 377: 101-102.

2. NcNeely E., Mordukhovich I., Staffa S. et al. Legacy health effects among never smokers exposed to occupational secondhand smoke. PLos One. 2019;14(4): e0215445. D01: 10.1371/journal.pone.0215445. 3. Capewell S., $0^{\prime}$ Flaherty M. Rapid mortality falls after risk-factor changes in populations/Lancet. 2011;378:752-753.

4. McAlinden K.D., Sohal S.S., Sharma P. There can be smoke without fire: warranted caution in promoting electronic cigarettes and heat not burn devices as a safer alternative to cigarette smoking. ERJ Open Research. 2019;5:00114-2019. doi:10.1183/23120541.00114-2019.

5. Oakes J.M., Fuchs R.M., Gardner J.D. et al. Nicotine and the reninangiotensin system. Am J Physiol Regul Integr Comp Physiol. 2018;315(5):R895-R906.5. doi:10.1152/ajpregu.00099.2018.

6. Hackshaw A., Morris J.K., Boniface S. et al. Low cigarette consumption and risk of coronary heart disease and stroke: meta-analysis of 141 cohort studies in 55 study reports. BMJ. 2018;360:5855. 7. Lawrence H., Hunter A., Murray R. et al. Cigarette smoking and the occurrence of influenza-Systematic review. J Infect. 2019;79(5):401-6. doi:10.1016/j.jinf.2019.08.014.

8. Girard D., Delgado-Eckert E., Schaffner E. et al. Longterm smoking cessation and heart rate dynamics in an aging healthy cohort: Is it possible to fully recover? Environ Res. 2015; 143 (A): 39-48.

9. GBD 2015 Risk Factors Collaborators. Global, regional, and national comparative risk assessment of 79 behavioural, environmental and occupational, and metabolic risks or clusters of risks, 1990-2015: a systematic analysis for the Global Burden of Disease Study 2015. Lancet. 2016; 388(10053):1659-1724.

\section{ORCID and contributionship:}

Natalia V. Borisova: 0000-0001-9583-3424 A, D, F

Sardana V. Markova: 0000-0003-3860-7230 ${ }^{B, D, E}$

Irina Sh. Malogulova: 0000-0003-0687-7949 C, D, E

\section{Conflict of interest:}

The Authors declare no conflict of interest.

\section{CORRESPONDING AUTHOR}

\section{Natalia V. Borisova}

INSTITUTE OF MEDICINE, NORTH-EASTERN FEDERAL UNIVERSITY, YAKUTSK, RUSSIA

27 0yunskogo st., 677000, Yakutsk, Russia

tel:+7 924 166-96-83

e-mail: smnsvfu@mail.ru

Received: 19.07 .2020

Accepted: 12.01 .2021

A - Work concept and design, B - Data collection and analysis, C - Responsibility for statistical analysis,

D-Writing the article, $\mathbf{E}$-Critical review, $\mathbf{F}$ - Final approval of the article 